\title{
Improving the assessment of the breeding value of pigs based on the use of BLUP methods and genomic analysis
}

\author{
Alexey Novikov ${ }^{1, *}$, Elena Suslina ${ }^{1}$, Grigorii Pokhodnya ${ }^{2}$, Yriy Breslavetz ${ }^{2}$, and Alexander \\ Breslavetz $^{2}$ \\ ${ }^{1}$ All-Russian Research Institute of Breeding of the Ministry of Agriculture of the Russian Federation, \\ Russia \\ ${ }^{2}$ Belgorod State Agricultural Univerisity named after V. Gorin, pos. Mayskiy, Russia
}

\begin{abstract}
The present paper presents the preliminary results of experiments to improve the evaluation of the breeding value of sows by such qualities as multiple births in live-born piglets, the number of business piglets at weaning at 30 days of age, and the safety of the litter. The evaluation of the breeding value of sows was carried out based on the use of BLUP methods and genomic analysis. It was found that the reliability of assessing the breeding value of sows increases significantly when both factors are taken into account: the use of genotypes of candidate genes ESR and PRLR and BLUP evaluation.
\end{abstract}

\section{Introduction}

The modern stage of improving breeding work in animal husbandry is characterized by the introduction into practice of high-tech methods based on the use of genetic and information technologies. Among the most promising methods are the genomic assessment of breeding value and the BLUP method using mathematical processing of data on the productive and other qualities of both the animal itself and its numerous relatives.

In the first case, the genetic potential of animal productivity is determined by identifying the degree of genetic determination of breeding traits and specific genes involved in one way or another associated with these traits. By means of special experiments, to date, many genes associated with certain traits, both productive qualities and others, are no less important for obtaining products, have been identified. So, by now, characterized by the onset of many infectious diseases, the identification of genes that affect the body's resistance, both general and specific, is of particular relevance. In pig breeding, it is this aspect that has the greatest impact on the profitability of production. The complexity of genomic assessment lies in the fact that many genes affect quantitative traits, which include productivity, resistance, stress resistance, and effective use of feed. The direction and degree of their influence depend not only on the genetic, hereditary basis of the organism, but also on the influence of numerous external factors, i.e. from the summed, additive effects of genetic and paratypical factors. This means that in each specific case, a specific account of the degree of their impact on the

\footnotetext{
${ }^{*}$ Corresponding author: novikov-41@bk.ru
} 
attribute is needed. The task is difficult. Therefore, the stake is on the fact that it is not always possible to identify breeding and usable value with a high degree of certainty using only genetic technologies.

The method for assessing the breeding value of animals using the BLUP procedure - the best linear unbiased forecast is based on the mathematical calculation of the breeding values by constructing indices. The indices are based on the values of animal breeding traits, their weight coefficients, taking into account the selective and economic significance, as well as factors affecting the manifestation of traits. The breeding value of an animal is calculated by solving the formed equation, i.e. index and is expressed as a numerical value. Based on the resulting value, the animal occupies a certain place in the list of evaluated animals, which makes it possible to clearly understand its ranking position in the population. Maximum consideration of all factors to determine the breeding value, incl. genetic with the involvement of relatives, paratypical, regional, environmental allows for a more reliable assessment of both breeding and usability of animals. However, this method also has some costs that reduce the reliability of the estimate. First of all, these are inaccuracies in the primary recording of data, calculating the degree of influence of genetic and paratypical factors due to the objective reality of differentiated growth, development of individuals in different conditions, different technologies for their breeding and obtaining products, possible errors in the examination of origin and other unpredictable factors.

The shortcomings in assessing animals, both in the first and in the second cases, can be significantly reduced by combining these methods to obtain an integrated indicator of the breeding value of the proband. It is for this purpose that we have planned to conduct a long experiment in the pig breeding industry.

This article presents the preliminary results of experiments to improve the assessment of the breeding value of sows.

\section{Materials and methods}

In order to obtain objective, reliable results, it is planned to study the above assessment methods when creating new breeding achievements in pig breeding for several generations. This methodological approach makes it possible to more accurately trace the genetic trend of the heritability of traits, especially with low coefficients of heritability and, in particular, such as reproductive qualities, viability and resistance of animals. The choice of this type of animal is based on the possibility of using methodological techniques that can be most effectively and accurately applied only on this type of farm animals. Such characteristics of pigs as multiple births of up to 16 or more piglets in one farrowing, early maturity - reaching the maturity of 6-8 months, allow not only to more accurately study all aspects of the influence of hereditary qualities, but also quickly know the results of this influence. These qualities also make it possible to use such a methodologically important technique as the study of the features of the manifestation of genetic potential when using animals at different stages of their productive use in practically the same conditions. In connection with the receipt from one sow of two or more farrowings within a relatively short period of time, it becomes possible to evaluate both boars and sows, especially the latter, at various physiological (ontogenetic) periods of their life.

In this work, the goal was to study the possibility of developing a more accurate method for assessing the breeding value of sows by reproductive qualities based on the results obtained by them during the first farrowing. In particular, we took into account such indicators as multiple births in live-born piglets, the number of business piglets at weaning at 30 days of age, and the safety of offspring. The possibility of developing a method for evaluating sows based on the results of the first farrowing that reliably and positively correlates with the results of subsequent farrowings will speed up the selection process by 
1.5-2 times. In pig breeding, with the existing renewal of commercial herds within 2, and often even 1.5 years, the use of this method is especially important in terms of increasing the profitability of this industry by increasing the meat yield from one sow per year by $50-60 \%$.

\section{Results and discussion}

1. Formation of the initial group of sows of large white breed with the duration of use on the farm not less than 3 - 4 farrowings with multiple births in live births ranging from 7 or more heads.

2. Obtaining the offspring of the original group, in particular the first generation gilts, by the method of purebred breeding.

3. Evaluation of the breeding value of sows of the first generation by the method of genomic analysis, taking into account their genotype according to candidate genes that determine reproductive qualities according to the results of the first farrowing.

4. Evaluation of the breeding value of sows involved in paragraph 3 by the BLUP method, approved by the EEC Board.

5. Evaluation of the breeding value of sows involved in paragraph 3 by an integrated method using the results of genomic evaluation and BLUP method.

In accordance with the research methodology carried out in the selection and hybrid center APC "Gorin collective Farm", Belgorod region, Belgorod region from a herd of sows of large white breed, numbering more than 800 heads, 109 heads were selected for the experiment.

When selecting, reproductive qualities were taken into account with a predominant reference point to the final indicator - the output of business piglets for weaning. Particular attention was also paid to such indicators as idleness, fertility, the number of stillborn and weak-born. As a rule, sows with a high, not less than 95\% fertility, no blanks, no stillborns and low-born sows in litters with multiple births of 7 or more live births were allowed for selection. Table 1 presents the average data for the original generation of sows.

Table 1. Average data of reproductive qualities of sows of the initial generation.

\begin{tabular}{|c|c|}
\hline Breed & Large white \\
\hline Number of heads & 109 \\
\hline Number of farrowings on average & $4.2 \lim 2-6$ \\
\hline Multiple births in live births, head. & $12.5 \lim 7-16$ \\
\hline Number of piglets at weaning, head & $10.0 \lim 8-12$ \\
\hline Safety, $\%$ & 80.0 \\
\hline
\end{tabular}

Based on the data presented in table 1, the group of sows selected for obtaining the 1st generation was characterized by average rates of multiple births and a slightly underestimated indicator of the number of piglets in the nest at weaning. The preservation of the offspring is $80.0 \%$. This fact indicates that in the future, with the genetic improvement of this herd, special attention will be paid to such a trait as the natural resistance of animals.

In order to study the possibility of using genomic analysis to predict the breeding value of animals, each of the sows in the group was tested by PCR for the presence of allelic variants of the ESR and PRLR genes. According to studies by numerous authors, these genes - ESR - estrogen and PRLR - prolactan receptors determine the reproductive qualities of sows, namely, the number of piglets born and preserved for weaning in the litter. In table 2, these data are presented depending on the genotypes of sows for the ESR gene. 
Table 2. Reproductive abilities of sows with different ESR genotypes

\begin{tabular}{|c|c|c|c|c|}
\hline Genotype & $\begin{array}{c}\text { Number of } \\
\text { heads }\end{array}$ & Plurality, heads & $\begin{array}{c}\text { Number of piglets to } \\
\text { weaning, animals }\end{array}$ & $\begin{array}{c}\text { Preservation of } \\
\text { offspring, } \%\end{array}$ \\
\hline AA & 24 & $12.7 \pm 0.272$ & $10.0 \pm 0.087^{*}$ & 78.7 \\
\hline BB & 21 & $12.3 \pm 0.362$ & $9.7 \pm 0.176^{*}$ & 78.8 \\
\hline AB & 64 & $12.4 \pm 0.169$ & $10.2 \pm 0.123$ & 82.2 \\
\hline
\end{tabular}

These tables show that animals with different genotypes differ somewhat in terms of both multiple fertility and the number of piglets in the nest at weaning. A low degree of reliability $(\mathrm{B}=0.95)$ of the difference between sows with genotypes AA and BB for multiple births 0.4 heads and piglets for weaning - 0.3 heads. The best results in terms of the safety of piglets and their number for weaning in sows with the AB genotype. A similar analysis was carried out in relation to the influence on the reproductive qualities of sows by the PRLR gene (Table 3).

Table 3. Reproductive abilities of sows with different RPRL genotypes.

\begin{tabular}{|c|c|c|c|c|}
\hline Genotype & $\begin{array}{c}\text { Number of } \\
\text { heads }\end{array}$ & Plurality, heads & $\begin{array}{c}\text { Number of piglets to } \\
\text { weaning, animals }\end{array}$ & $\begin{array}{c}\text { Preservation } \\
\text { of } \\
\text { offspring, } \%\end{array}$ \\
\hline AA & 26 & $12.6 \pm 0.233$ & $9.8 \pm 0.176$ & 77.7 \\
\hline BB & 17 & $12.4 \pm 0.292$ & $9.8 \pm 0.156$ & 79.0 \\
\hline AB & 66 & $12.5 \pm 0.183$ & $10.2 \pm 0.104$ & $87.6^{*}$ \\
\hline
\end{tabular}

Sows with different PRLR genotypes do not differ in terms of multiple births, there is no difference between sows with genotypes AA and BB in terms of the number of piglets for weaning. Unreliable difference of +0.4 piglets in sows with genotype $A B$ in the number of piglets for weaning. In this group - the best safety of piglets for weaning $-87.6 \%$.

From the sows of the original group by mating them with boars of a large white breed, the first generation of animals was obtained to study the possibility of determining the breeding value of sows using the methods of genomic analysis and the BLUP method according to the results of the first farrowing. For the experiment, 63 heads with different indicators of reproductive qualities were selected from among the selected and raised sows. For the purpose of a more detailed study of the influence of the ESR and PRLR genes on reproductive qualities and their assessment by the BLUP method, selected sows - 63 heads were divided into two experimental groups that significantly differ from each other both in terms of multiple births and the number of piglets for weaning. Table 4 shows the characteristics of the reproductive qualities of these groups and the results of their assessment by the BLUP method.

Table 4. Index score of sows by the BLUP method with high and low reproductive qualities.

\begin{tabular}{|c|c|c|c|c|}
\hline $\begin{array}{c}\text { Experienced } \\
\text { group }\end{array}$ & $\begin{array}{c}\text { Number of } \\
\text { heads }\end{array}$ & Plurality, heads & $\begin{array}{c}\text { Number of heads } \\
\text { to wean, head }\end{array}$ & $\begin{array}{c}\text { Complex } \\
\text { index }\end{array}$ \\
\hline 1 & 43 & 12.0 and $>$ & 10.0 and $>$ & $108.76^{*}$ \\
\hline 2 & 20 & 10.0 and $<$ & 8.0 and $<$ & 102.10 \\
\hline
\end{tabular}

* $\mathrm{B}=0.95$

The data of BLUP assessments - the complex indices of reproductive sows in the experimental groups differ by 6.66 units. The difference is significant at the lowest probability threshold. The obtained experimental data confirm the possibility of using the 
BLUP method to assess the breeding value of sows by reproductive qualities. However, the low confidence threshold between the experimental groups does not give a complete basis for a more accurate prediction of the breeding value of sows by this method based on the results of their first farrowing.

In order to develop a more accurate method, the experimental groups of animals were evaluated by the BLUP method, taking into account their genotypes for ESR and PRLR genes. The results of these evaluations are presented in Tables 5 and 6 .

Table 5. Index score of sows with different reproductive qualities depending on their genotype for the ESR gene.

\begin{tabular}{|c|c|c|c|c|c|}
\hline \multirow{2}{*}{$\begin{array}{c}\text { Genoty } \\
\text { pe }\end{array}$} & \multicolumn{2}{|c|}{ Experienced group 1 } & \multicolumn{2}{c|}{ Experienced group 2 } & \multirow{2}{*}{$\mathrm{d}$} \\
\cline { 2 - 5 } & $\begin{array}{c}\text { Number } \\
\text { of heads }\end{array}$ & Index & $\begin{array}{c}\text { Number } \\
\text { of heads }\end{array}$ & Index & \\
\hline 1 & 2 & 3 & 4 & 5 & 6 \\
\hline AA & 5 & 107.78 & 7 & 102.76 & 5.02 \\
\hline BB & 3 & 109.77 & 3 & 101.00 & 8.77 \\
\hline AB & 36 & 112.73 & 11 & 102.27 & $10.46^{* *}(3-5)$ \\
\hline
\end{tabular}

Table 6. Index score of sows with different reproductive qualities depending on their genotype for the PRLR gene.

\begin{tabular}{|c|c|c|c|c|c|}
\hline \multirow[b]{2}{*}{ Genotype } & \multicolumn{2}{|c|}{ Experienced group 1} & \multicolumn{2}{|c|}{ Experienced group 2} & \multirow[b]{2}{*}{ d } \\
\hline & $\begin{array}{c}\text { Number of } \\
\text { heads }\end{array}$ & Index & $\begin{array}{l}\text { Number } \\
\text { of heads }\end{array}$ & Index & \\
\hline AA & 15 & 115.59 & 6 & 109.97 & 5.62 \\
\hline BB & 6 & 93.94 & 3 & 96.40 & -2.46 \\
\hline $\mathrm{AB}$ & 28 & 109.73 & 9 & 109.96 & -0.23 \\
\hline
\end{tabular}

The results of the experiment presented in the tables show that the ESR gene showed a significant relationship between the reproductive qualities of sows and the allelic $\mathrm{AB}$ variant. The difference in BLUP scores between the experimental groups is more than 10 units at $\mathrm{B}=$ 0.99. For genotypes AA and BB, the difference is insignificant. The results of the analysis of the index assessment of the breeding value of animals in the experimental groups, taking into account their genotypes for the PRLR gene, do not confirm any dependence of the assessment indicators. In both groups, the indices of animals with different genotypes are practically the same.

\section{Conclusion}

The research results presented in this article allow us to conclude that the genomic forecast of the breeding value of sows in terms of reproductive qualities based on the use of genotypes of the candidate genes ESR and PRLR without BLUP assessment does not reflect their real breeding value. At the same time, the breeding value of sows is also insufficiently accurately estimated by the BLUP method without taking into account their genotype for the ESR gene. The reliability of the estimate is significantly improved when both factors are taken into account. We believe that our proposed assessment methodology is correct. However, for the final confirmation, it is necessary to conduct studies in this aspect on a larger number of animals, taking into account the results of assessing the breeding value of sows involved in the experiment during subsequent farrowings and evaluating them by offspring in the next generations. 


\section{References}

1. M.F. Rothschild, Metods to determine genetic diversity. Discovery conference proceedings, Nashville, TN, November 2 (1999)

2. Max F. Rothschild, Advances in pig molecular genetics, genemapping and genomics, Iowa State University, Ames, Iowa S0011. USA (2004)

3. M.F. Rothschild, Genome mappind in livestock: A jorney, not a distination. Proceedings of the future genetics for the animal industry. St.Louis. MO. May 4 is a publication.

4. T.H. Shon, M.E. Rothschild, J.Anim Sci 75, 3138-3142

5. The methodology for assessing the breeding value of pigs (approved by the decision of the Board of the Eurasian Economic Commission dated November 24, 149 (2020)

6. VG Kozlovsky, II Tonyshev, Pig breeding 6, 10-12 (1982)

7. E.N. Suslina, Animal husbandry 9, 6-8 (2008)

8. S.N. Aleinik, G.S. Pokhodnya, A.A. Novikov, S.M. Mirzaev, Fundamentals of breeding in pig breeding, 181 (Belgorod: Publishing house LLC IPC "Politerra", 2020)

9. V.Ya. Gorin, G.S. Pokhodnya, A.A. Fainov, E.G. Fedorchuk, A.N. Ivchenko, T.A. Malakhova, Animal husbandry 5, 24-26 (2014)

10. V.Ya. Gorin, G.S. Pokhodnya, A.A. Fainov, E.G. Fedorchuk, T.A. Malakhova, Animal husbandry 5, 21-23 (2014)

11. A.T. Mysik, G.S. Pokhodnya, T.A. Malakhova, A. Yu. Kalinin, N.I. Zhernakova, M.Yu. Skorkina, Animal husbandry, 3, 24-26 (2020)

12. A.T. Mysik, G.S. Pokhodnya, A.V. Kosov, Yu.P. Breslavets, Animal husbandry 11, 22-25 (2020)

13. G.S. Pokhodnya, Pig breeding, 1, 768 (2019)

14. V.P. Zhabinskaya, N.S. Trubchaninova, G.S. Pokhodnya, D.V. Korobov, V.I. Kotarev, O.E. Tat'yanicheva, N.B. Ordina, International of Advanced Biotechnology and Research (VABR) ISSN 0976-2612, ISSN 2278-599X, 10(1), 47-53 (2019)

15. A.M. Khokhlov, A.S. Smirnova, V.I. Gerasimov, G.S. Pokhodnya, N.I. Zhernakov, P.P. Kornienko, Pig breeding and pork production technology: Collection of scientific papers of the scientific school of Professor G.S. Walk around 10, 200-203 (Belgorod, Publishing house of OOO IPC "Potiterra", 2016) 